\title{
Using soils for accident dosimetry: a preliminary study using optically stimulated luminescence from quartz
}

\author{
By H. Fujita ${ }^{1,2, *}$, M. Jain ${ }^{2}$ and A. S. Murray ${ }^{3}$ \\ ${ }^{1}$ Nuclear Fuel Cycle Engineering Laboratories, Japan Atomic Energy Agency, Tokai-mura, Naka-gun, Ibaraki 319-1194, Japan \\ ${ }^{2}$ Radiation Research Division, Ris $\varnothing$ National Laboratory for Sustainable Energy, Technical University of Denmark, P.O. 49, 4000 Roskilde, \\ Denmark \\ ${ }^{3}$ Nordic Laboratory for Luminescence Dating, Department of Earth Sciences, Aarhus University, Ris $\varnothing$ DTU, 4000 Roskilde, Denmark
}

(Received November 26, 2009; accepted in revised form December 12, 2010)

Thermoluminescence / Optically stimulated luminescence / Retrospective dosimetry / Soil / Quartz /

Minimum detection limit

Summary. The optimum conditions of preheat temperature, stimulation temperature, etc. in the single-aliquot regenerative optically stimulated luminescence (SAR OSL) method were examined specifically for measuring background dose in natural quartz extracted from soils collected around Tokai-mura in Japan. The objective was to assess the potential of SAROSL dosimetry using soils for retrospective assessment of a radiation accident. Variation in dose with depth was also measured.

The SAR data showed good reproducibility and dose recovery, and there was no evidence of fading of the quartz signal based on "delayed" dose recovery experiments. The minimum detection limit (MDL) dose was about $0.1 \mathrm{~Gy}$.

The dose dependence was measured using both the above SAR OSL protocol as well as a SAR thermoluminescence (TL, violet emission) protocol. The background doses were generally in the range of the MDL to several Gy, and no clear trend in dose depth profile was observed.

From these results, we conclude that SAR OSL dosimetry using natural quartz extracted from soil could be used to evaluate the dose of an accident.

\section{Introduction}

Presently, the single-aliquot regenerative-dose optically stimulated luminescence protocol (SAR OSL; Murray and Wintle, 2000) is widely used to determine the equivalent dose (De) to quartz in the field of dating and retrospective dosimetry (Ramzaev et al., 2008; Murray et al., 2008). However, Tsukamoto et al. (2003) showed that there are several problems in dating using unheated Japanese volcanic quartz by the SAR OSL procedure.

In this study, we investigated the performance of the SAR protocol for dose measurement (not for dating) using Japanese quartz extracted from soil. The SAR protocol was then used to estimate the naturally accumulated dose in quartz samples extracted from the top $100 \mathrm{~mm}$ depth of the

\footnotetext{
*Author for correspondence (E-mail: fujita.hiroki@jaea.go.jp).
}

soil. The De values obtained by SAR OSL were compared with those obtained using violet thermoluminescence (VTL) signals.

\section{Experimental}

Soil samples were collected from three different locations (Higashiishikawa, Nagasuna and Terunuma) around Tokaimura, Ibaraki Prefecture in Japan as part of our monitoring plan. The samples were taken from the depth of $0-100 \mathrm{~mm}$ at each location using stainless steel tubes to prevent exposure to sunlight.

In the laboratory, all columns were separated into $10-\mathrm{mm}$ depths. These samples were treated by the same procedure as described in the previous paper (Fujita and Hashimoto, 2006). All procedures were performed in dim red light. $\mathrm{Pu}-$ rity of the quartz samples was determined using infraredemitting LEDs which showed an undetectable signal (Jain et al., 2001).

All measurements were performed using a Ris $\emptyset$ TL-OSLDA-15 reader (Bøtter-Jensen et al., 2003) equipped with ${ }^{90} \mathrm{Sr} /{ }^{90} \mathrm{Y}$ beta source delivering a dose rate of $0.10 \mathrm{~Gy} \mathrm{~s}^{-1}$ to the quartz sample (as determined by calibration with a reference gamma source of ${ }^{137} \mathrm{Cs}$ ). For OSL measurements, stimulation light was provided by blue emitting LEDs (blueLEDs, $470 \pm 30 \mathrm{~nm}, \sim 50 \mathrm{~mW} \mathrm{~cm}^{-2}$ ), and both OSL and VTL signals were recorded with a Hoya U-340 filter in the optical detection system.

The SAR protocol was defined by measurement of OSL characteristics using Higashiishikawa quartz illuminated by a SOL2 solar simulator to eliminate naturally accumulated OSL signals. After illuminating the quartz, the aliquots were irradiated with $5 \mathrm{~Gy}$ and then were used in the experiments. The SAR protocol involves making repeated OSL measurements $\left(\mathrm{L}_{x}\right)$ on each aliquot to obtain a dose response curve and comparing the natural (or artificial) luminescence intensity $\left(\mathrm{L}_{N}\right)$ with this curve to determine the equivalent dose (De), while monitoring changes in sensitivity (Murray and Wintle, 2000).

For investigating the thermal stability of OSL signals, three aliquots of the sample were preheated at various temperatures for $10 \mathrm{~s}$ before the OSL was measured, then a test 
dosed OSL was measured to monitor changes in sensitivity $\left(\mathrm{L}_{x} / \mathrm{T}_{x}\right.$ measurements). All measurements were conducted with a storage time of $1000 \mathrm{~s}$ after irradiation to prevent the influence of afterglow signals (which are unstable at room temperature) on OSL measurements.

Minimum detection limit (MDL) is partly dependent on the sensitivity of the sample, as well as the experimental conditions such as counting efficiency and sample mass. One practical approach to defining the MDL is to estimate the background dose from a bleached sample. Such background doses were measured using five aliquots (extracted from Higashiishikawa soil) bleached using the SOL 2 solar simulator.

The dose profiles of three samples were estimated using the SAR OSL protocol outlined on the basis of a preheat plateau to determine the influence of sunlight bleaching on quartz. In order to interpret the influence, the profiles using the same samples were also measured by VTL dosimetry because the VTL component could be hard to bleach by sunlight in comparison with the OSL one, except for the components in the lower temperature area.

\section{Results and discussion}

\subsection{Thermal stability}

A pulse annealing curve averaged using three aliquots of the sample with associated uncertainties of $1 \sigma$ (standard deviation) is shown in Fig. 1. The OSL signal was estimated by integrating the counts in the first $0.4 \mathrm{~s}$ after subtracting the average background estimated from the data in the last $2 \mathrm{~s}$ of the OSL curve (Fig. 1, inset). The corrected OSL signal intensity $\left(\mathrm{L}_{x} / \mathrm{T}_{x}\right)$ showed a two-step decrease with preheat temperature. A component of the OSL signal was unstable and decreased with large scatter at a preheat temperature of between 30 and $120^{\circ} \mathrm{C}$. The more stable component showed a plateau after preheating at between 140 and $200^{\circ} \mathrm{C}$ and then underwent a rapid decrease leading to almost complete depletion at a preheat temperature of $320^{\circ} \mathrm{C}$. These trends

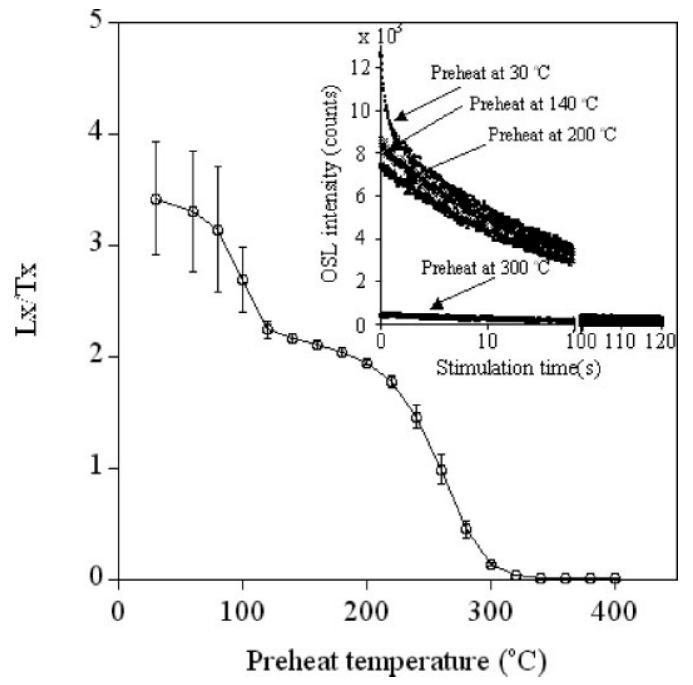

Fig. 1. "Pulse annealing" curve of the OSL from natural quartz collected at Higashiishikawa. Inset shows OSL decay curves with preheat temperature.

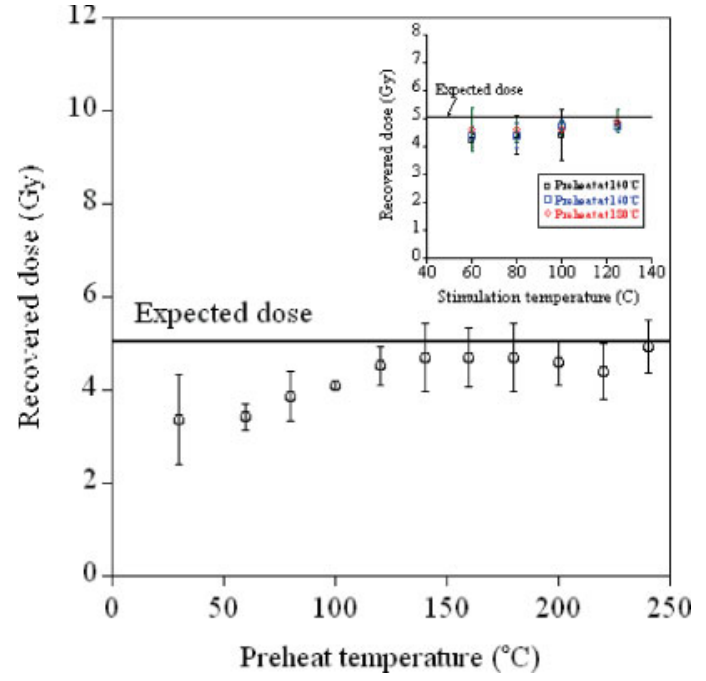

Fig. 2. Dependence of measured dose on preheat temperature in a dose recovery test. Inset shows the dependence of recovered dose on stimulation temperature.

are probably related to two or more traps giving rise to the OSL signal.

To determine the appropriate conditions of preheat treatment, a dose recovery test was conducted using Higashiishikawa quartz. The aliquots were stored for $3 \mathrm{~d}$ before dose recovery measurement using SAR to mimic an accident dosimetry scenario. The averaged results of the dose recovery test with preheat temperature are plotted in Fig. 2, with associated uncertainties of $1 \sigma$ (standard deviation). In these experiments, three aliquots were used at each preheat temperature and $30^{\circ} \mathrm{C}$ was chosen as the stimulation temperature. The recovered doses increased with preheating at between 30 and $140{ }^{\circ} \mathrm{C}$ and then followed a plateau up to a preheat temperature of $180^{\circ} \mathrm{C}$ followed by a decreasing tendency. From these results, the preheat temperature could be chosen in the range of $140-180^{\circ} \mathrm{C}$. However, the recovered doses in the range of the preheat temperature were still underestimated. The dependence of the recovered dose on stimulation temperature $\left(60-125^{\circ} \mathrm{C}\right)$ was then investigated

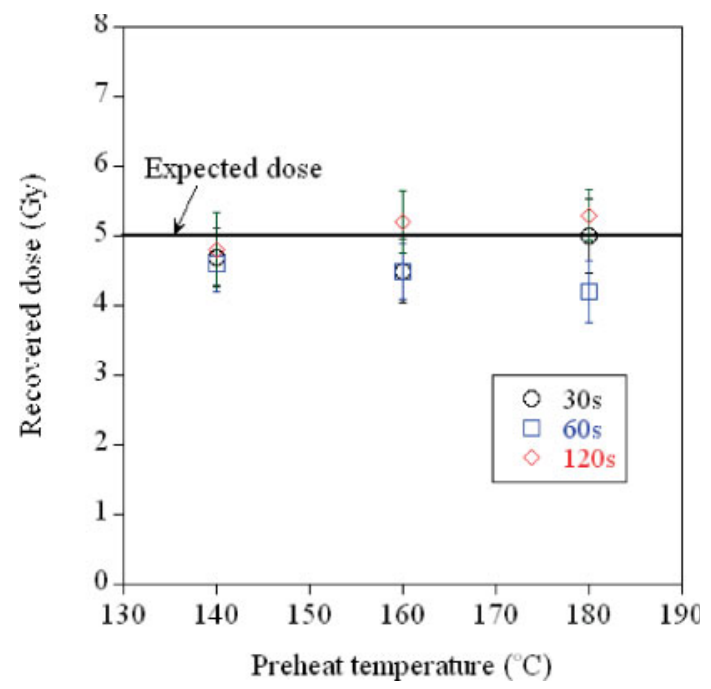

Fig. 3. Dependence of recovered dose on preheat temperature and time in a dose recovery test. 
using preheating at between 140 and $180^{\circ} \mathrm{C}$ as shown in the inset of Fig. 2. Stimulation temperatures above $125^{\circ} \mathrm{C}$ were not examined in this study because the OSL components at the temperature could include VTL components. The recovered doses increased with stimulation temperature at each preheat temperature for $10 \mathrm{~s}$. From the figure, it was considered that stimulation at $125^{\circ} \mathrm{C}$ was suitable for the dose estimation. Moreover, the preheat time was varied between 30 and $120 \mathrm{~s}$ for a preheat temperature of $140-180^{\circ} \mathrm{C}$ using a stimulation temperature of $125^{\circ} \mathrm{C}$. The averaged results using three aliquots are shown with associated uncertainties of $1 \sigma$ (standard deviation) in Fig. 3. There was no significant correlation between the preheat time and recovered dose, but the estimated dose after the preheat treatment at $180^{\circ} \mathrm{C}$ for $30 \mathrm{~s}$ corresponded to the given dose.

From these results, preheat treatment at $180^{\circ} \mathrm{C}$ for $30 \mathrm{~s}$ and stimulation at $125^{\circ} \mathrm{C}$ were selected for the SAR OSL protocol in later sections.

\subsection{Depth profile of naturally accumulated doses in soil using SAR OSL and SAR VTL dosimetries}

The background dose from the bleached sample gave a mean of $0.06 \mathrm{~Gy}$ and a standard error of $0.02 \mathrm{~Gy}$. Assuming that we would be able to detect a naturally accumulated dose equal to or greater than three standard errors above the mean, we estimated an MDL of $\sim 0.12$ Gy for this sample.

Fig. 4 shows the SAR OSL dose profile with sampling depth. The dose profiles were averaged by three aliquots at each depth and are shown with associated uncertainties of 1 $\sigma$ (standard deviation). The estimated doses were below the detection limit using quartz extracted from Terunuma soil. The dose profile of Higashiishikawa quartz was independent of sampling depth, whereas the other dose profile of Nagasuna quartz changed by depth. The reason why these dose profiles were different might be interference by environmental conditions. The Higashiishikawa sample was collected from a shrine field that was relatively undisturbed by people, whereas the other soil sample was collected from a residential area that might have been interfered with by people. The different dose profiles may have been caused by environmental conditions.

The dose profile was also estimated by VTL measurement. No natural signals of the VTL peak at $160^{\circ} \mathrm{C}$ could be found in any of the VTL measurements as suggested in a previous paper (Fujita and Hashimoto, 2007). The results confirmed that the VTL dosimetry using the peak at $160^{\circ} \mathrm{C}$ could evaluate, without background effects, the dose accumulated in a site affected by an accident.

Table 1 summarizes naturally accumulated doses as the average of all depths at each sampling point. The experimental errors of accumulated doses were derived from three aliquot analyses. Generally speaking, the doses estimated by the SAR OSL protocol showed lower accumulated doses than those by the SAR VTL protocol using the VTL peak at $215^{\circ} \mathrm{C}$ except for Terunuma quartz. In principle, if there is no fading of the luminescence sources during the storage period after heating or bleaching, the estimated doses using quartz should agree with each other. However, the doses estimated by SAR OSL measurements were $30-40 \%$ lower than those by SAR VTL measurements. The results suggest that

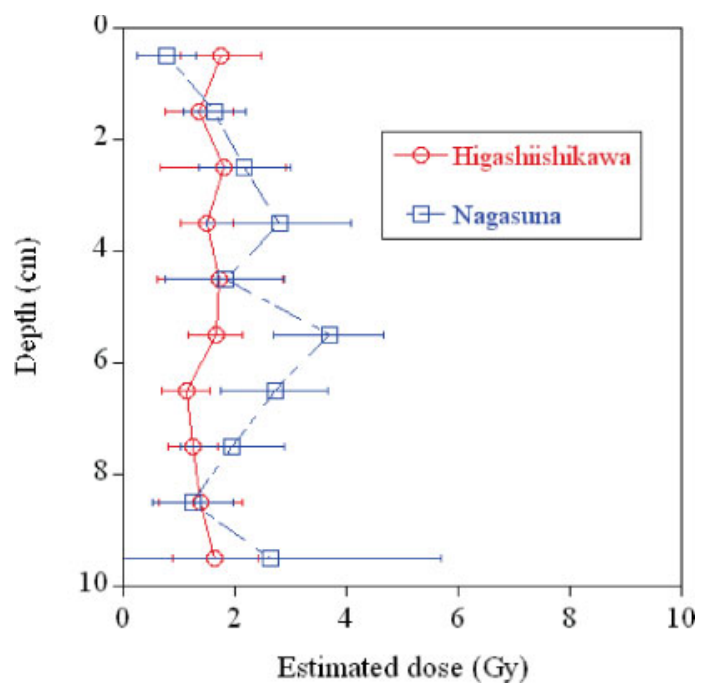

Fig. 4. SAR-OSL dose depth profiles for two soil-sampling points plotted against sampling depth.

Table 1. Naturally accumulated doses averaged at each sampling point.

\begin{tabular}{lcc}
\hline Sampling point & SAR-OSL (Gy) & SAR-VTL (Gy) \\
\hline Higashiishikawa & $0.97 \pm 0.34$ & $1.4 \pm 0.34$ \\
Nagasuna & $1.4 \pm 0.69$ & $2.4 \pm 0.93$ \\
Terunuma & $<$ detection limit & - \\
\hline
\end{tabular}

the soil was partially bleached during deposition and storage time because the OSL components may have originated from the light-sensitive portion of the VTL peak at $215^{\circ} \mathrm{C}$.

Quartz from Terunuma soil emitted a huge VTL peak at $305^{\circ} \mathrm{C}$ which widened at around $180^{\circ} \mathrm{C}$, and so it was difficult to estimate the dose by SAR VTL dosimetry. In contrast, the doses estimated by SAR OSL were below the detection limits. These results indicate that the SAR OSL protocol using older Japanese surface soil has an advantage for accident dosimetry to measure the artificially irradiated dose separately from the huge naturally accumulated dose.

\section{Conclusion}

The dose estimation method using SAR OSL measurements was investigated using natural quartz extracted from Japanese soils. The results indicated that dosimetry based on SAR OSL measurements could be used for retrospective dosimetry. Moreover, the MDL of the SAR OSL was determined to be $\sim 0.12$ Gy for the samples.

On the other hand, the dose profile in soil was not dependent on depth from the surface and varied between the SAR OSL and SAR VTL protocols. The difference may have been due to environmental conditions. The results from Terunuma quartz suggest that the SAR OSL protocol using older Japanese soil has an advantage for accident dosimetry compared with SAR VTL dosimetry because SAR OSL could measure the estimated dose but SAR VTL could not.

Further work is necessary to determine whether the developed SAR OSL protocol could also be used for retrospective dosimetry using natural quartz extracted from other places in Japan. 
Acknowledgment. The author sincerely thanks Mr. Yuji Kokubun of the Japan Atomic Energy Agency for his help in this work.

\section{References}

1. Aitken, M. J.: An Introduction to Optical Dating: The Dating of Quaternary Sediments by the Use of Photon-stimulated Luminescence. Oxford University Press, Oxford (1998).

2. Bøtter-Jensen, L., Anderson, C. E., Duller, G. A. T., Murray, A. S.: Developments in radiation, stimulation and observation facilities in luminescence measurements. Radiat. Meas. 37, 535 (2003).

3. Fujita, H., Hashimoto, T.: Influence of radioluminescence on optically stimulated luminescence from natural quartz grains. Radioisotopes 55, 117 (2006).

4. Fujita, H., Hashimoto, T.: Usability of VTL from natural quartz grains for retrospective dosimetry. Radiat. Prot. Dosim. 123(2), 143 (2007).
5. Jain, M., Singhvi, A. K.: Limits of depletion of blue-green light stimulated luminescence in feldspars: implications for quartz dating. Radiat. Meas. 33, 883 (2001).

6. Murray, A. S., Wintle, A. G.: Luminescence dating of quartz using an improved single-aliquot regenerative-dose protocol. Radiat. Meas. 32, 57 (2000).

7. Murray, A. S., Buylaert, J. P., Henriksen, M., Svendsen, J. I., Mangerud, J.: Testing the reliability of quartz OSL ages beyond the Eemian. Radiat. Meas. 43, 776 (2008).

8. Ramzaev, V., Bøtter-Jensen, L., Thomsen, K. J., Andersson, K. G., Murray, A. S.: An assessment of cumulative external doses from Chernobyl fallout for a forested area in Russia using the optically stimulated luminescence from quartz inclusions in bricks. J. Environ. Radioact. 99, 1154 (2008).

9. Tsukamoto, S., Rink, W. J., Watanuki, T.: OSL of tephric loess and volcanic quartz in Japan and an alternative procedure for estimating De from a fast OSL component. Radiat. Meas. 37, 459 (2003). 